\title{
The effects of low tidal ventilation on lung strain correlate with pulmonary compliance
}

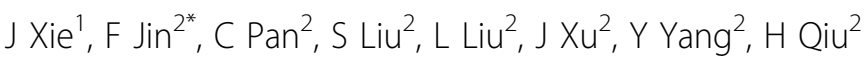 \\ From ESICM LIVES 2015 \\ Berlin, Germany. 3-7 October 2015
}

\section{Background}

The effect of changing tidal volume on mortality of acute respiratory distress syndrome (ARDS) is determined by pulmonary compliance. We aimed to investigate the effects of different tidal volumes on lung strain in patients with ARDS.

\section{Methods}

Nineteen patients were divided into high $\left(\mathrm{C}_{\text {high }}\right.$ group $)$ and low pulmonary compliance $\left(\mathrm{C}_{\text {low }}\right.$ group) groups based on their pulmonary compliance values $\left(0.6 \mathrm{ml} /\left[\mathrm{cmH}_{2} \mathrm{O} \cdot \mathrm{kg}\right]\right)$. End-expiratory lung volumes (EELV) with different tidal volumes $\left(\mathrm{V}_{\mathrm{T}}\right.$ at baseline and at $6,8,10$ and $12 \mathrm{ml} / \mathrm{kg}$ predicted body weight $[\mathrm{PBW}]$ ) were measured by nitrogen wash-in/washout. Lung strain was calculated as the ratio between tidal volume and EELV.

\section{Results}

The mean baseline EELV and pulmonary compliance values were $1873 \mathrm{ml}, 0.31$ and $0.65 \mathrm{ml} /\left(\mathrm{cmH}_{2} \mathrm{O} \cdot \mathrm{kg}\right)$, respectively; all differences were statistically significant between the two groups. For all participants, a positive correlation was found between pulmonary compliance and EELV $\left(\mathrm{r}^{2}=0.238, p=0.034\right)$. When the tidal volume increased gradually from $6 \mathrm{ml} / \mathrm{kg}$ to $12 \mathrm{ml} / \mathrm{kg}$ also increased gradually, from $0.31 \pm 0.27$ to $0.52 \pm$ 0.46 , which represented a positive correlation $\left(\mathrm{r}^{2}=\right.$ $0.956, p<0.01)$. In the $C_{\text {high }}$ group, there were no significant differences in strain between the tidal volume ventilation of $6 \mathrm{ml} / \mathrm{kg}$.PBW and the volumes of 8 and $10 \mathrm{ml} / \mathrm{kg}$. PBW. However, strain increased significantly with the tidal volume of $12 \mathrm{ml} / \mathrm{kg}$.PBW. The mean lung strain was $<0.27$ with ventilation at tidal volumes of 6 and $8 \mathrm{ml} / \mathrm{kg} . \mathrm{PBW}$, whereas it was $>0.27$ with volumes of 10 and $12 \mathrm{ml} / \mathrm{kg}$.PBW. In contrast, in the $C_{\text {low }}$ group, there were no significant differences in strain between the different tidal volumes. However, mean lung strain was $\geq 0.27$ for each tidal volume. In addition, $60 \%$ of patients' lung strain measured $\geq 0.27$ even with tidal volume ventilation of $6 \mathrm{ml} / \mathrm{kg}$.PBW.

\section{Conclusions}

Pulmonary compliance affected the effect of tidal volume on strain in ARDS patients, which suggests that setting individual tidal volumes based on pulmonary compliance and strain may be more rational.

\section{Trial Registration}

Clinicaltrials.gov identifier NCT01864668.

\section{Authors' details}

${ }^{1}$ Nanjing Zhongda Hospital, Southeast Unversity, Critical Care Medicine, Najing, China. ${ }^{2}$ Nanjing Zhongda Hospital, Southeast University, Nanjing, China.

Published: 1 October 2015

doi:10.1186/2197-425X-3-S1-A310

Cite this article as: Xie et al:: The effects of low tidal ventilation on lung strain correlate with pulmonary compliance. Intensive Care Medicine Experimental 2015 3(Suppl 1):A310. 